\title{
A QUESTÃO DA SELETIVIDADE E O DIAGNÓSTICO DO USO E TRÁFICO DE DROGAS EM CURITIBA, PARANÁ
}

\author{
LA CUESTIÓN DE LA SELECTIVIDAD Y EL DIAGNÓSTICO DEL \\ USO Y EL TRÁFICO DE DROGAS EN CURITIBA, PARANÁ
}

\author{
Doacir Gonçalves de Quadros ${ }^{1}$ \\ Daniel Jose De Figueiredo ${ }^{2}$
}

\begin{abstract}
RESUMO
O presente trabalho tem por objetivo verificar a hipótese de seletividade na repressão aos crimes de drogas. Parte da doutrina sustenta que essa repressão estaria ligada aos aspectos de visibilidade da infração, adequação do autor ao estereótipo do criminoso, incapacidade do agente em beneficiar-se da corrupção ou prevaricação e vulnerabilidade à violência, o que direcionaria a ação estatal para a parcela mais pobre da população. A pesquisa utiliza o método indutivo, partindo dos dados rendimento nominal mensal médio das pessoas de 10 anos ou mais de idade e de ocorrências policiais de uso e tráfico de drogas por bairro de Curitiba, Paraná, para um diagnóstico preliminar acerca da distribuição das ocorrências em função do rendimento e do espaço geográfico, seguindo-se de análises de regressão (linear múltipla e espacial), que indicaram que $35 \%$ da variação da taxa de ocorrências policiais relacionadas a tráfico de drogas pode ser explicada pela variação do número de domicílios permanentes em casa de cômodos, cortiço ou cabeça de porco e taxa de pretos e pardos, variáveis estas relacionadas aos aspectos da seletividade. Conclui-se, a final, que a análise estatística confere plausibilidade à hipótese testada.
\end{abstract}

\section{PALAVRAS-CHAVE:}

Direitos Fundamentais. Lei anti-drogas. Seletividade na Repressão.

\footnotetext{
${ }^{1}$ Doutor em Sociologia (UFPR) na área de concentração Cultura e Poder, Graduação em Ciências Sociais e Mestrado em Sociologia Política (UFPR). Professor de Ciência Política e do Programa de Pós-Graduação Stricto Sensu em Direito: Mestrado Acadêmico do Centro Universitário UNINTER. Professor dos cursos em EaD do Uninter. Pesquisador associado a Asociación Latinoamericana de Investigadores en Campañas Electorales (ALICE). Pesquisador associado a Associação Nacional de Pós-Graduação e Pesquisa em Ciências Sociais (ANPOCS). Pesquisador associado a COMPOLITICA - Associação brasileira de pesqusadores em Comunicação Política. Pesquisador associado a ALACIP - Associação Latino Americana de Ciência Política. Pesquisador associado a Associação Brasileira de Ciência Política - ABCP. Pesquisador associado a Rede de Estudos Empírico em Direito - REED.

${ }^{2}$ Mestre em Direito (bolsista pelo Centro Universitário Internacional UNINTER, Curitiba, PR, 2020); Especialista em Direito Penal e Processual Penal (bolsista pela Academia Brasileira de Direito Constitucional, Curitiba, PR, 2015). Graduado em Direito pela Pontifícia Universidade Católica do Paraná, Curitiba, PR, 2011; Tecnólogo em Processamento de Dados com Ênfase em Análise de Sistemas pela Universidade Estácio de Sá, Rio de Janeiro, RJ, 2002.
} 


\section{RESUMEN}

Este artículo tiene como objetivo verificar la hipótesis de selectividad en la represión de los delitos de drogas. Parte de la doctrina argumenta que esta represión estaría vinculada a aspectos de visibilidad del delito, idoneidad del perpetrador al estereotipo del perpetrador, incapacidad del perpetrador para beneficiarse de la corrupción o prevaricación, y vulnerabilidad a la violencia, lo que dirigiría la acción estatal a la parte más vulnerable. pobres de la población. La investigación utiliza el método inductivo, basado en datos del ingreso nominal mensual promedio de personas de 10 años o más y de incidentes policiales de uso y tráfico de drogas en Curitiba, Paraná, para un diagnóstico preliminar sobre la distribución de incidentes en ingresos y espacio geográfico, seguidos de análisis de regresión (múltiples lineales y espaciales), que indicaron que el 35\% de la variación en la tasa de incidentes relacionados con drogas relacionados con la policía puede explicarse por la variación en el número de hogares permanentes casa de habitaciones, vivienda o cabeza de cerdo y tasa negra y marrón, variables relacionadas con aspectos de selectividad. En conclusión, el análisis estadístico da verosimilitud a la hipótesis probada.

\section{PALABRAS CLAVE:}

Derechos fundamentales. Ley antidrogas. Selectividad en represión.

\section{INTRODUÇÃO}

A construção de uma sociedade protegida do uso de drogas, quer sejam elas as lícitas ou as tornadas ilícitas, é um contrassenso. As drogas estão presentes desde os primórdios da humanidade. São usadas em todo o mundo de forma massiva e, estando relacionadas ao prazer, dão ensejo a verdadeiras "cruzadas moralizantes". Esbarra-se aqui em questões relacionadas a direitos fundamentais, dentre eles, a liberdade, intimidade e autonomia do indivíduo. ${ }^{3}$

O proibicionismo relacionado a algumas drogas cria crimes sem vítimas, criminalizando a mera posse de drogas tornadas ilícitas à escolha da Administração ou sua negociação entre adultos maiores e capazes. A lei não deve tolher do indivíduo suas possibilidades de escolha, suas opções pessoais, suas liberdades. Nas palavras de Karam, “o Estado Democrático não pode substituir o indivíduo nas decisões que dizem respeito apenas a si mesmo." ${ }^{4}$ Neste sentindo o

\footnotetext{
${ }^{3}$ Cf. KARAM, Maria Lucia. "Guerra às Drogas” e criminalização da pobreza. In: Estudos críticos sobre o sistema penal: homenagem ao Professor Doutor Juarez Cirino dos Santos por seu 70ªniversário. Curitiba: LedZe, 2012. passim.

${ }^{4}$ Ibid
} 
Estado deve priorizar a conservação das condições necessárias para a criação de um Estado Democrático de direito ${ }^{5}$.

O Brasil possuía, em junho de 2016, 176.808 presos por tráfico de drogas, o que representava aproximadamente $25 \%$ da população carcerária do País. ${ }^{6}$ Karam sustenta que este universo é composto, majoritariamente, por integrantes das camadas mais baixas da sociedade. Afirma que a "guerra às drogas" é uma guerra declarada contra os mais vulneráveis produtores, comerciantes e usuários. Os inimigos são os pobres, os marginalizados, os desprovidos de poder e a eventual punição de um ou outro grande traficante não altera significativamente os alvos preferenciais do sistema: ${ }^{7}$

O motor do crescimento nos últimos anos dessas prisões superlotadas de pobres, marginalizados, desprovidos de poder, no mundo inteiro, são fundamentalmente processos e condenações por crimes relacionados a drogas.

Intui-se, portanto, uma correlação entre as condições socioeconômicas de determinada população e as prisões por tráfico de drogas. O objetivo deste estudo será, portanto, a verificação da hipótese da existência de uma seletividade na repressão estatal relacionada aos crimes de tráfico de drogas. A pesquisa utilizará o método indutivo ${ }^{8}$, partindo da análise da distribuição das ocorrências de uso e tráfico e drogas em Curitiba, Paraná, para a análise de regressão estatística, considerando variáveis socioeconômicas relacionadas à questão da seletividade. A abordagem será quantitativa (análise estatística).

\section{A SELETIVIDADE NOS CRIMES RELACIONADOS A DROGAS}

A legislação brasileira não estabelece um critério objetivo que diferencie o traficante do usuário. A distinção será feita pelo juiz e "atenderá à natureza e à quantidade da substância apreendida, ao local e às condições em que se desenvolveu a ação, às circunstâncias sociais e

\footnotetext{
${ }^{5}$ Cf. SILVA Leilianne Francielle. O princípio da intervenção mínima como problemática social: a dimensão constitucional, penal e moral. Revista Juris Poiesis ano 19, n $^{\circ} 21$, set.-dez.. 2016.

6 Dados obtidos no sítio do Departamento Penitenciário Nacional. Disponível em: <http://depen.gov.br/DEPEN/depen/sisdepen/infopen/relatorios-analiticos/br/br >. Acesso em: 17 abr. 2019.

${ }^{7}$ Cf. KARAM, Maria Lucia. Op. Cit. passim.

${ }^{8}$ Cf. GIL, Antônio Carlos. Métodos e Técnicas de Pesquisa Social. 6. ed. São Paulo: Atlas, 2008. p. 10-11.
} 
pessoais, bem como à conduta e aos antecedentes do agente". ${ }^{9}$ Na prática brasileira, a primeira avaliação para a distinção entre uso e tráfico é feita pela polícia quando efetua a prisão.

Segundo D`Elia Filho, a criminalização primária é a exercida pelo Poder Legislativo e consiste no "ato e efeito de sancionar uma lei penal material que incrimina ou permite a punição de certas pessoas." No caso em estudo a criminalização primária ocorreu com a promulgação da atual Lei de Drogas. A criminalização secundária, por sua vez, “é a ação punitiva exercida sobre pessoas concretas, que se desenvolve desde a investigação policial até a imposição e a execução de uma pena e que, necessariamente, se estabelece através de um processo seletivo." 10

A criminalização secundária é exercida por policiais, promotores, juízes, advogados, agentes penitenciários. A seletividade ocorre na medida em que não "é impossível para os gestores da criminalização secundária realizarem o projeto 'faraônico' de criminalização primária previsto em todas as leis penais de um país." Não sendo possível processar e julgar todas as pessoas que usam ou traficam drogas, é necessário optar pela inatividade ou pela seleção. D'Elia Filho afirma que "esse poder de seleção corresponde, fundamentalmente, às agências policiais". ${ }^{11}$

A seleção daqueles que serão presos por tráfico de drogas se dará pela análise da chamada "cifra negra", ou seja, dos crimes que são cometidos e que não chegam ao conhecimento das autoridades e daqueles que, apesar de chegarem ao conhecimento das autoridades, não resultarão em processo criminal. ${ }^{12}$

A “cifra negra" se dá pela diferença entre a criminalidade real e a aparente ${ }^{13}$ e pode ser explicada por quatro fatores preponderantes: "a visibilidade da infração, a adequação do autor

\footnotetext{
${ }^{9}$ BRASIL. Lei ${ }^{\circ} 11.343$, de 23 de agosto de 2006. Institui o Sistema Nacional de Políticas Públicas sobre Drogas - Sisnad; prescreve medidas para prevenção do uso indevido, atenção e reinserção social de usuários e dependentes de drogas; estabelece normas para repressão à produção não autorizada e ao tráfico ilícito de drogas; define crimes e dá outras providências. Disponível em: < http://www.planalto.gov.br/ccivil_03/_ato20042006/2006/lei/111343.htm >. Acesso em: 17 abr. 2019.

${ }^{10}$ Cf. D’ELIA FILHO, Orlando Zaccone. Acionistas do Nada. Rio de Janeiro: Revan, 2007. p 16.

${ }^{11}$ Ibid.

${ }^{12}$ Ibid., p. 17.

${ }^{13}$ Cf. DE CASTRO, Lola Anyar, apud D’ELIA FILHO, op Cit.. p 18.
} 
ao estereótipo do criminoso; a incapacidade do agente em beneficiar-se da corrupção ou prevaricação; e a vulnerabilidade à violência." 14

No que se refere à visibilidade da infração, os espaços em que o tráfico de drogas opera nos bairros de maior renda é completamente diferente daqueles em que o tráfico opera nos lugares mais carentes. O tráfico em bairros ricos se dá em áreas fechadas, privadas, longe do acesso da polícia. Nas áreas mais carentes, o tráfico ocorre em becos, vielas, casebres, lugares em que não há dificuldade para intervenções policiais. ${ }^{15}$

O fator de adequação ao estereótipo do criminoso, vem da relação entre crime e miséria. Ainda se considera a pobreza como causa do crime e o traço definidor da imagem do delinquente é seu status social. O estereótipo se consuma "na figura do jovem negro, funkeiro, morador de favela, próximo do tráfico de drogas, vestido com boné, cordões, portador de algum sinal de orgulho ou de poder e de nenhum sinal de resignação ao desolador cenário de miséria e fome que o circunda." 16

A seleção dos que serão alcançados pela prisão por tráfico de drogas continua com a incapacidade do indivíduo de beneficiar-se da corrupção ou da prevaricação. O tráfico de drogas se vale de uma grande rede de colaboradores, muitos deles de menor importância no macro sistema e facilmente substituíveis, "a ponta final do comércio de drogas proibidas". São, por exemplo, as "mulas", que fazem o vai-e-vem da droga, os "fogueteiros", que auxiliam na vigilância das comunidades para avisar a chegada da polícia, os "vapores" e os "esticas", que participam da venda em pequenas quantidades. São presas fáceis que não podem se beneficiar da corrupção ou da prevaricação porque não dispõem de dinheiro ou prestígio. ${ }^{17}$

O espaço público é o outro fator da seletividade. Nos bairros pobres a atuação da polícia não encontra a mesma resistência e objeção encontradas nos bairros ricos. A estratégia de policiamento não é a mesma para ambos os casos. O enfrentamento bélico, típico da chamada "guerra às drogas" não se amolda ao modo e estilo de vida das classes altas. ${ }^{18}$

\footnotetext{
${ }^{14} \mathrm{Cf}$. THOMPSON, Augusto apud D’ELIA FILHO, Op Cit.. p 18.

${ }^{15}$ Cf. D’ELIA FILHO, Op. Cit., p. 18

${ }^{16}$ Ibid., pp. 19 e ss.

${ }^{17}$ Ibid., pp. 21-22.

18 Ibid., p. 22.
} 
Para a consecução da seletividade, acresça-se a imprecisão da própria lei brasileira na tentativa de distinção de traficantes e usuários. O exacerbado grau de discricionariedade que decorre do texto legal abre a possibilidade de se opor, a simples usuários enquadrados como traficantes, uma pesada carga jurídico-processual, inclusive com a possibilidade de privação de liberdade. Diferentemente do traficante, o usuário pode fazer jus, por exemplo, à transação penal e à suspensão condicional do processo. ${ }^{19}$

Também não há qualquer distinção objetiva entre pequenos e grandes traficantes, de modo que todos estão sujeitos a pesadas penas, várias causas de aumento (interestadualidade ou transnacionalidade do tráfico, por exemplo) e a severos regimes de cumprimento devido à equiparação dos crimes de tráfico aos crimes hediondos. De acordo com a lei 11.343 faculta-se ao Juiz, somente no momento da dosimetria da pena, considerar a quantidade de substâncias apreendidas, sem qualquer objetividade. ${ }^{20}$

Os aspectos de seletividade citados - visibilidade da infração, a adequação do autor ao estereótipo do criminoso; a incapacidade do agente em beneficiar-se da corrupção ou prevaricação; a vulnerabilidade à violência e imprecisão da lei - são bem ilustrados pela fala de um policial civil, trazida da pesquisa de Grillo et al:

\begin{abstract}
A subjetividade dos critérios abre espaço para a reificação das pré-concepções policiais sobre quem sejam os traficantes e os usuários. Os critérios enunciados por alguns policiais civis, durante a pesquisa de campo em uma delegacia, revelam alguns aspectos da seletividade policial: "Se um cara é pego com drogas, mesmo que em pequena quantidade, e estiver em um lugar onde todo mundo sabe que tem uma boca, se ele morar naquela comunidade, ele pega tráfico. Se o cara for lá de Duque de Caxias, mesmo que esteja com uma quantidade maior, vai pegar uso, pois a gente sabe que ele não tava vendendo ali. Mas aí a gente pede a carteira de trabalho. Se ele tiver emprego, tudo bem, mas se não tiver emprego, tava comprando droga com que dinheiro? Era pra revender, né? Aí ele pega tráfico.” [entrevistado A., policial civil]. 21
\end{abstract}

Para D’Elia Filho, a seletividade importa no encarceramento das classes de menor renda, que auferem com o tráfico de pequenas quantidades de drogas uma ínfima parcela do gigantesco

\footnotetext{
${ }^{19}$ Cf. LECHENAKOSKI, Bryan Breno. A Subjetividade na Diferenciação entre o Usuário e o Traficante Critérios Perniciosos para o Acusado. Revista Núcleo Jurídico. Florianópolis. v. 1. p. 9-31. 2017. p. 15.

${ }^{20}$ Cf. art. 42. BRASIL. Lei no 11.343 , de 23 de agosto de 2006. Institui o Sistema Nacional de Políticas Públicas sobre Drogas - Sisnad; prescreve medidas para prevenção do uso indevido, atenção e reinserção social de usuários e dependentes de drogas; estabelece normas para repressão à produção não autorizada e ao tráfico ilícito de drogas; define crimes e dá outras providências. Disponível em: < http://www.planalto.gov.br/ccivil_03/_ato20042006/2006/lei/l11343.htm >. Acesso em: 17 abr. 2019.

${ }^{21}$ Cf. GRILLO, Carolina Christoph; POLICARPO, Frederico; VERÍSSIMO, Marcos. A "dura" e o "desenrolo": efeitos práticos da nova lei de drogas no Rio de Janeiro. Revista de Sociologia e Política. Curitiba, v. 19, n. 40, p. 135-148, out. 2011.
} 
montante de recursos movimentados pelo tráfico internacional, ${ }^{22}$ estimados pela Global Financial Integrity (GFI) entre USD 426 e 652 bilhões em 2014, dados estes que podem estar subdimensionados, tendo em vista a natural dificuldade de mesurar atividades que, por serem ilícitas, obviamente são encobertas. ${ }^{23}$

\section{PROCEDIMENTOS METODOLÓGICOS}

O trabalho foi realizado utilizando-se o software livre e de código aberto $\mathrm{GeoDa}^{24}$ e os softwares proprietários Microsoft Exce $^{25}$ e Action Sat ${ }^{26}$. O GeoDa fornece uma interface gráfica aos métodos de análise exploratória de dados espaciais, além de estatísticas de autocorrelação espacial para dados agregados e análise básica de regressão espacial para dados de pontos e polígonos. O Microsoft Excel permite a manipulação de tabelas e o uso de várias funções matemáticas e estatísticas. O Action Sat permite uma série de análises estatísticas, inclusive análise de regressão.

A base de dados de renda e de população por bairro de Curitiba está disponível no Instituto de Pesquisa e Planejamento Urbano de Curitiba (IPPUC). A variável de renda utilizada foi o "rendimento nominal mensal médio das pessoas de 10 anos ou mais de idade"27. Outros dados utilizados foram a "domicílios particulares permanentes - habitação em casa de cômodos,

\footnotetext{
${ }^{22}$ Cf. D’ELIA FILHO, Op. Cit., p. 22.

${ }^{23}$ Cf. GLOBAL FINANCIAL INTEGRITY (GFI) Transnational Crime and the Developing World. Washington, DC. 2017. p. 3. Disponível em: < https://www.gfintegrity.org/wp-content/uploads/2017/03/Transnational_Crimefinal.pdf >. Acesso em: 17 abr. 2019.

${ }^{24}$ Geoda. Versão 1.12.1.161. [S.1.]: The R Foundation for Statistical Computing, 2018.

${ }^{25}$ Microsoft Excel 2013. Versão 15.0.5075.1001. [S.1.]: Microsoft Corporation, 2013.

${ }^{26}$ Action Sat. Versão 3.6.331.450 build 7. São Carlos: Estatcamp Consultoria Estatística e Qualidade, 2019.

${ }^{27} \mathrm{Cf}$. IBGE. Soma do rendimento nominal mensal de trabalho com o proveniente de outras fontes. Disponível em:

< https://www.ibge.gov.br/apps/snig/v1/notas_metodologicas.html?loc=0 >. Acesso em: 04 jul. 2019.
} 
cortiço ou cabeça de porco"28 "população - cor/raça preta"29 e "população - cor/raça parda"30. Todos os dados foram obtidos a partir do aplicativo Infocuritiba ${ }^{31}$ e referem-se ao Censo de 2010.

Para o georreferenciamento, os dados vetoriais também foram obtidos no Instituto de Pesquisa e Planejamento Urbano de Curitiba (IPPUC) ${ }^{32}$. A escala não foi informada. O espaço geográfico da cidade de Curitiba é dividido em setenta e cinco bairros. De forma complementar, a fim de facilitar a localização dos bairros pelo leitor, um mapa da cidade com as divisões por bairro está disponível no anexo 1.

A base de dados de uso e tráfico de drogas por bairro de Curitiba foi obtida junto à Secretaria de Estado de Segurança Pública do Estado do Paraná (SESP/PR), em requerimento fundamentado na Lei de Acesso à Informação (Lei 12.527/2011). Os dados de uso e tráfico de drogas utilizados na pesquisa referem-se ao período de 2008 a 2017. A análise de um período de dez anos se presta a suavizar eventuais oscilações atípicas nas ocorrências registradas de um ano para outro. Além disto, uma amostra maior tem o poder indicar eventuais tendências com melhor precisão. Os dados foram normalizados pela população do bairro respectivo, de modo a se obter a taxa média de ocorrências por cem mil habitantes no período considerado. Em outras palavras, a média das ocorrências de 2008 a 2017 foi dividida pela população do bairro respectivo e multiplicada por 100.000 .

$\mathrm{O}$ arquivo vetorial dos bairros da cidade de Curitiba foi mesclado com as taxas médias de uso e tráfico de drogas e com os dados do rendimento nominal mensal médio das pessoas de 10 anos ou mais de idade. A estatística descritiva foi produzida em conjunto com boxplots e

\footnotetext{
${ }^{28}$ Cf. IBGE. Habitação em casa de cômodos, cortiço ou cabeça de porco - quando localizado em habitação que se caracteriza pelo uso comum de instalações hidráulica e sanitária (banheiro, cozinha, tanque etc.) com outras moradias e utilização do mesmo ambiente para diversas funções (dormir, cozinhar, fazer refeições, trabalhar etc.). Faz parte de um grupo de várias habitações construídas em lote urbano ou em subdivisões de habitações de uma mesma edificação, sendo geralmente alugadas, subalugadas ou cedidas e sem contrato formal de locação. Disponível em: < https://www.ibge.gov.br/apps/snig/v1/notas_metodologicas.html?loc=0 >. Acesso em: 04 jul. 2019.

29 Cf. IBGE. Pessoa que se declarou preta. Disponível em: < https://www.ibge.gov.br/apps/snig/v1/notas_metodologicas.html?loc=0 >. Acesso em: 04 jul. 2019.

30 Cf. IBGE. Pessoa que se declarou parda. Disponível em: < https://www.ibge.gov.br/apps/snig/v1/notas_metodologicas.html?loc=0 >. Acesso em: 04 jul. 2019.

31 Instituto de Pesquisa e Planejamento Urbano de Curitiba (IPPUC). Infocuritiba. Disponível em: < http://infocuritiba.ippuc.org.br/imp/ >. Acesso em 17 nov. 2018.

32 Instituto de Pesquisa e Planejamento Urbano de Curitiba (IPPUC). Disponível em: < http://ippuc.org.br/geodownloads/geo.htm >. Acesso em 17 nov. 2018.
} 
boxmaps, estes últimos visando a identificação de outliers e suas correspondentes visualizações no espaço geográfico municipal. Foi feita a análise de regressão linear multivariada, considerando a taxa média de tráfico de drogas como variável dependente e número de domicílios permanentes em casa de cômodos, cortiço ou cabeça de porco (DCCC) e a taxa de pretos e pardos (TXPP) como variáveis independentes, esta última obtida pela soma do número de pretos e pardos, divisão pela população do bairro respectivo e multiplicação por 100.000 . Por fim foi feita a análise de regressão espacial e a comparação entre os dois modelos propostos.

\section{ANALISE DO RENDIMENTO, USO E TRÁFICO DE DROGAS EM CURITIBA}

De acordo com o Instituto Brasileiro de Geografia e Estatística, atualmente o Brasil tem 5.570 municípios. ${ }^{33}$ Considerando o Índice de Desenvolvimento Humano Municipal ${ }^{34}$, Curitiba coloca-se na $10^{\mathrm{a}}$ posição dentre todos, colocando-se na restrita faixa de desenvolvimento humano muito alto. ${ }^{35}$

Em relação a drogas, Curitiba foi a primeira cidade do País a contar com uma Secretaria Municipal Antidrogas, criada pela Lei Municipal 12.667/08 com a atribuição de "articular ações de prevenção ao uso indevido de drogas e reinserção social de dependentes, bem como estabelecer parcerias com os órgãos públicos responsáveis pela repressão do tráfico de drogas, dentro da esfera municipal" ${ }^{36}$. Contudo, as ocorrências de uso e tráfico de drogas aumentaram significativamente, mesmo com a existência da Secretaria até 2014, ano em que foi extinta pela Lei Municipal 14.422/14:

\footnotetext{
${ }^{33}$ Disponível em: < https://cidades.ibge.gov.br/brasil/panorama >. Acesso em: 17 abr. 2019.

${ }^{34}$ Disponível em: < http://www.atlasbrasil.org.br/2013/pt/o_atlas/idhm/ >. Acesso em: 17 abr. 2019.

${ }^{35}$ Disponível em: < http://www.atlasbrasil.org.br/2013/pt/ranking/ >. Acesso em: 17 abr. 2019.

${ }^{36}$ Cf. art. $1^{\circ}$. CURITIBA. Lei no $12.667 / 08$, de 4 de abril de 2008. Cria a Secretaria Antidrogas Municipal - SAM, altera dispositivos da Lei $\mathrm{N}^{\circ} 7.671$, de 10 de junho De 1991, e suas alterações, e da Lei $\mathrm{N}^{\circ} 11.100$, de 21 de junho de 2004, que autoriza o executivo municipal a criar o Conselho Municipal de Políticas Sobre Drogas de Curitiba e dá outras providências. Disponível em: < https://leismunicipais.com.br/a/pr/c/curitiba/leiordinaria/2008/1267/12667/lei-ordinaria-n-12667-2008-cria-a-secretaria-antidrogas-municipal-sam-alteradispositivos-da-lei-n-7671-de-10-de-junho-de-1991-e-suas-alteracoes-e-da-lei-n-11100-de-21-de-julho-de-2004que-autoriza-o-executivo-municipal-a-criar-o-conselho-municipal-de-politicas-sobre-drogas-de-curitiba-e-daoutras-providencias?q=12.667 >. Acesso em: 17 abr. 2019.
} 
Gráfico 1: Ocorrências de uso e tráfico de drogas em Curitiba no período 2008-2017.

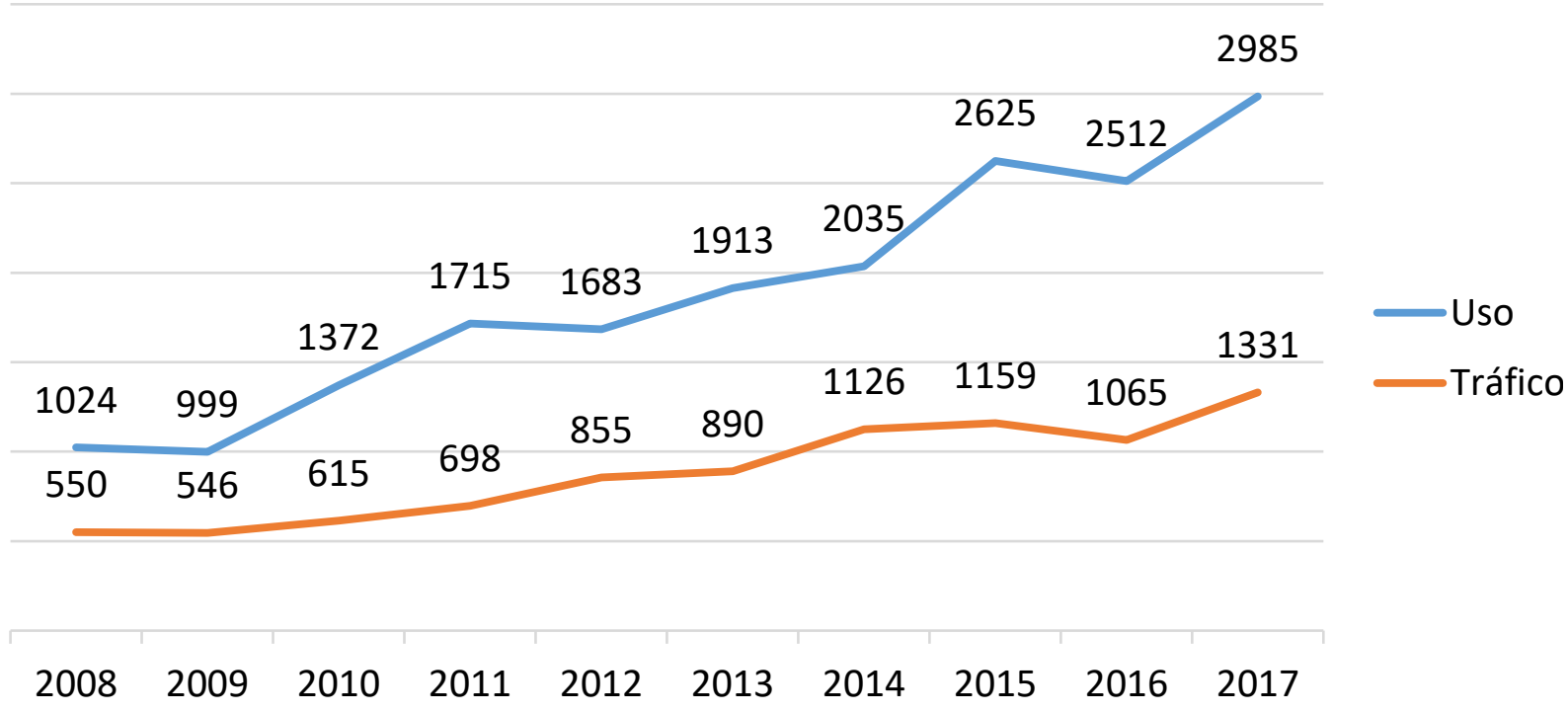

Fonte: o autor, com dados da SESP/PR e uso do software MS Excel.

O gráfico demonstra uma inicial estabilidade, seguida de uma tendência de alta. No período considerado, foram contabilizadas 18.683 ocorrências de uso e 8.835 ocorrências de tráfico de drogas.

Em relação ao rendimento das pessoas acima de $10 \operatorname{anos}^{37}$, a distribuição em Curitiba é heterogênea:

${ }^{37} \mathrm{Cf}$. IBGE. Soma do rendimento nominal mensal de trabalho com o proveniente de outras fontes. Disponível em: $<$ https://www.ibge.gov.br/apps/snig/v1/notas_metodologicas.html?loc=0 >. Acesso em: 04 jul. 2019. 
Figura 1 - BOXPLOT E BOXMAP REFERENTES AO RENDIMENTO NOMINAL MENSAL MÉDIO DAS PESSOAS DE 10 ANOS OU MAIS DE IDADE (2010),

\section{PADRONIZADO.}
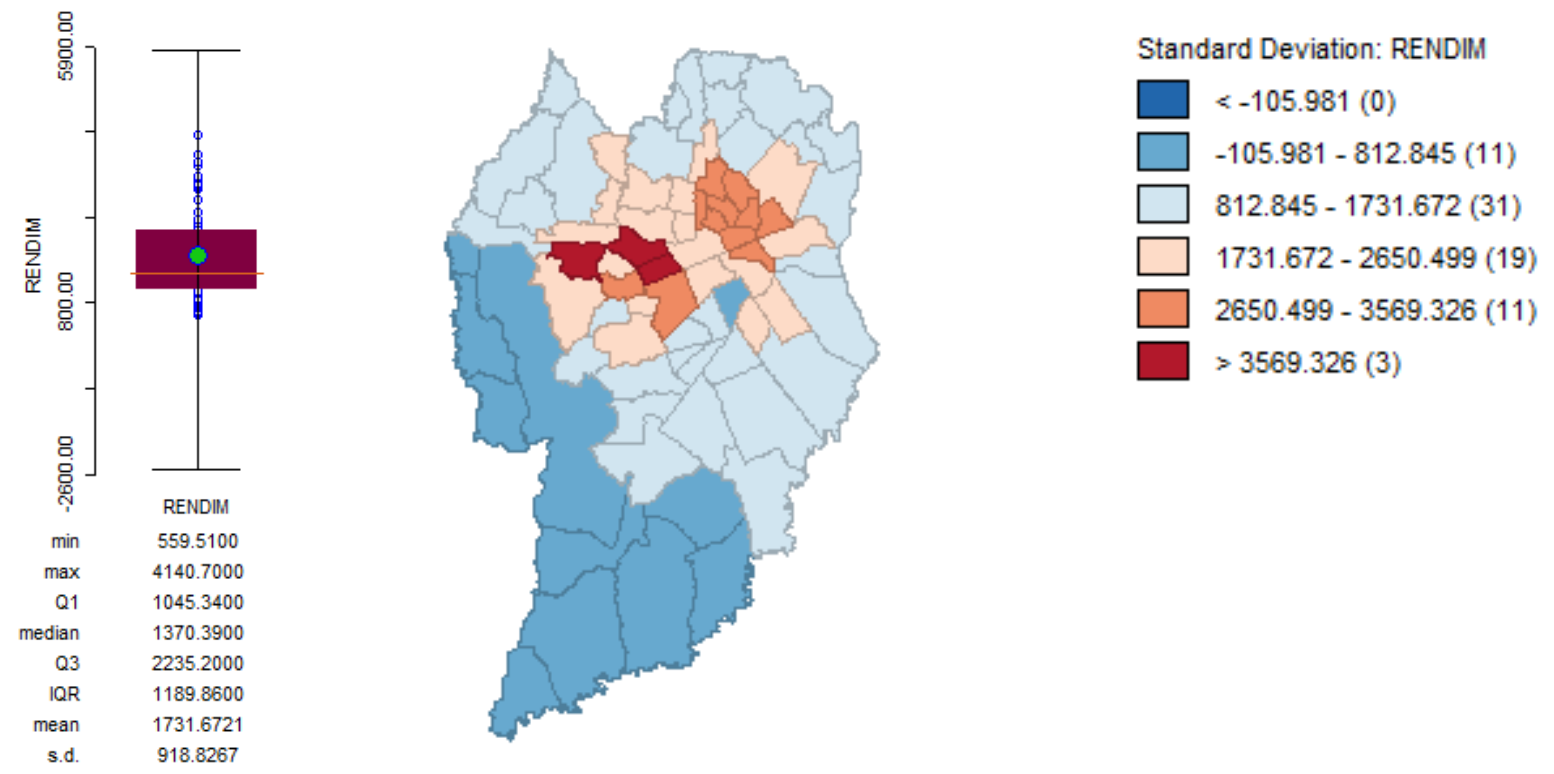

Fonte: o autor, com dados do IPPUC e uso do software Geoda.

O rendimento nominal mensal médio das pessoas de 10 anos ou mais de idade, de acordo com os dados do censo de 2010 (últimos dados disponíveis), varia entre $\mathrm{R} \$ 559,51$ e $\mathrm{R} \$$ 4.140,70. A média é de $\mathrm{R} \$ 1.731,67$ e o desvio padrão é de $\mathrm{R} \$ 918,82$.

Todos os 33 bairros em que as pessoas têm rendimentos superiores à média localizamse na porção central da cidade. A partir da região central, os níveis de renda decrescem para as extremidades do espaço geográfico, distribuindo-se por outros 42 bairros, em sua grande maioria periféricos.

A divisão das ocorrências policiais referentes a uso e tráfico de drogas (números absolutos) em função do rendimento nominal mensal médio das pessoas de 10 anos ou mais de idade, é ilustrada abaixo: 
Gráfico 2: Divisão das ocorrências de uso e tráfico de drogas em Curitiba no período 20082017 em relação ao rendimento nominal mensal médio das pessoas de 10 anos ou mais de idade.
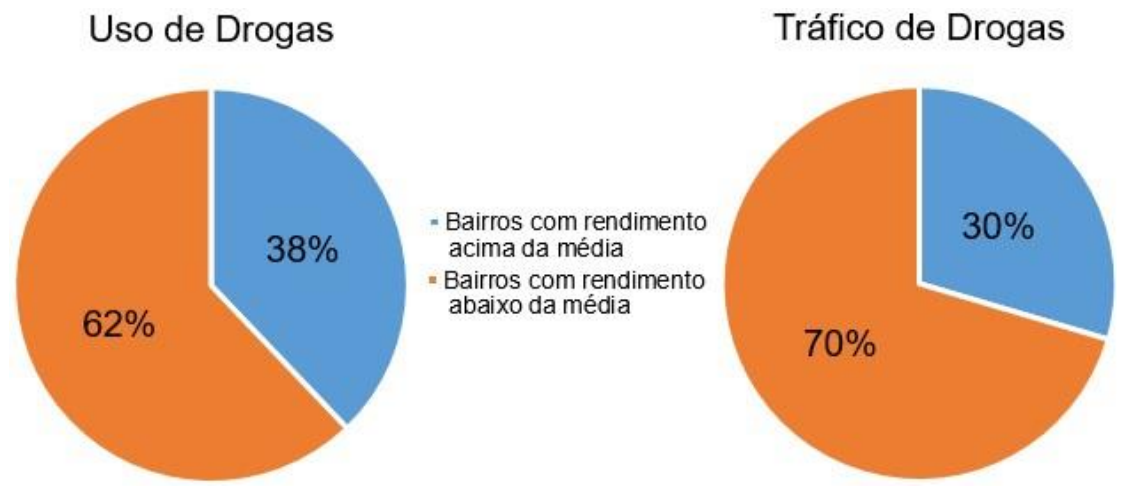

Fonte: o autor, com dados da SESP/PR e do IPPUC e uso do software MS Excel.

O gráfico demonstra que a maior concentração de ocorrências policiais relacionadas a drogas se dá em bairros com rendimento nominal mensal médio abaixo da média de Curitiba: $62 \%$ do total no caso de uso e $70 \%$ no caso de tráfico de drogas. 
Figura 2 - BOXPLOT E BOXMAP REFERENTES À VARIÁVEL TAXA MÉDIA DE USO DE DROGAS (2008-2017).
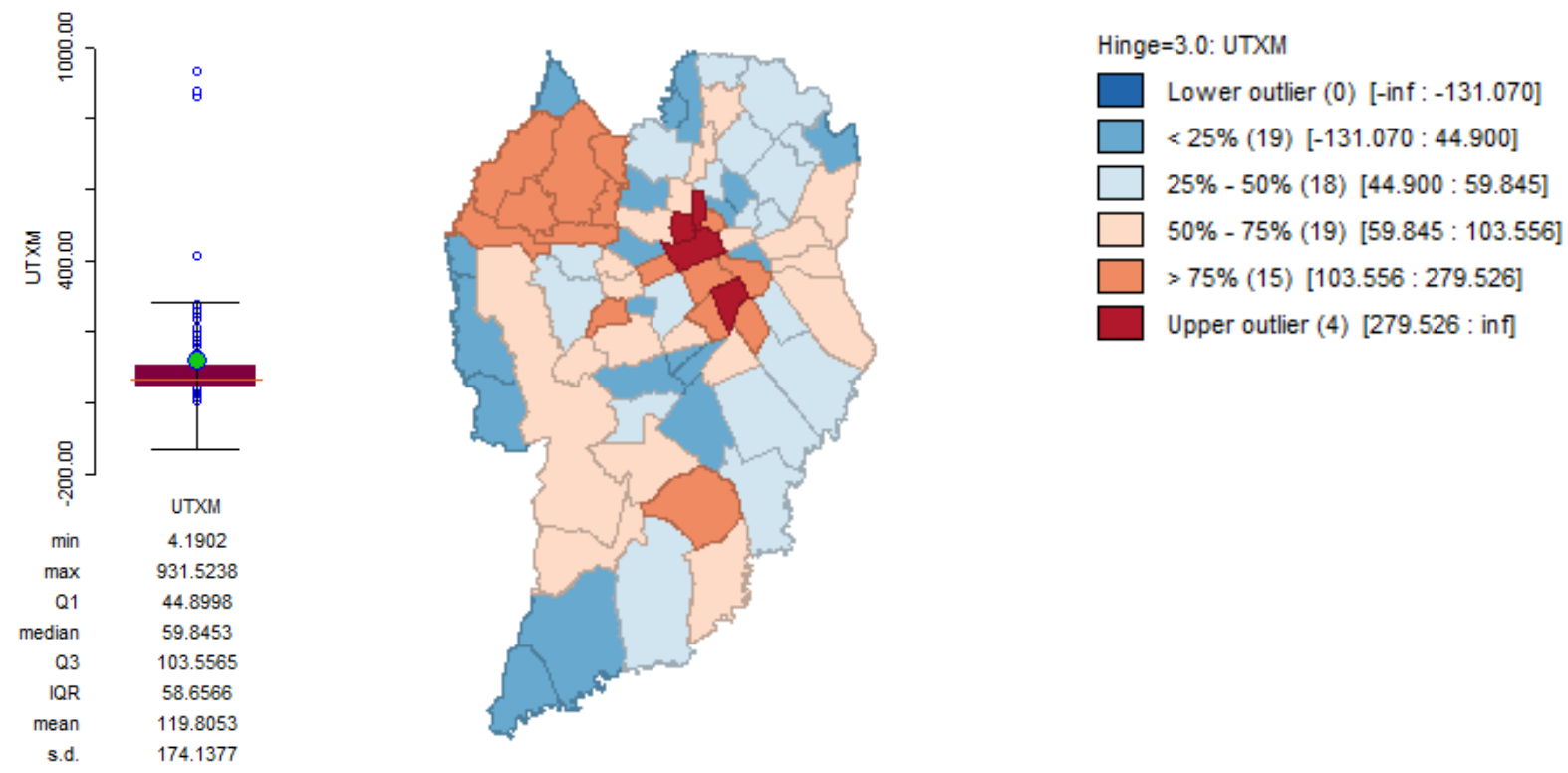

Fonte: o autor, com dados da SESP/PR e uso do software Geoda.

A análise dos dados indica que a taxa média de ocorrências de uso de drogas para o período de 2008 a 2017 varia entre 4,19 e 931,52 casos por cem mil habitantes. A média é de 199,80 ocorrências por cem mil habitantes. O limite superior (dado por Q3 + 3 x IQR) é igual a 279,52 casos por cem mil habitantes. Valores acima deste indicam observações atípicas (outliers). Neste caso, o gráfico indica a existência de quatro outliers: Centro, Centro Cívico, Prado Velho e São Francisco.

Dentre os outliers encontrados, três figuram entre os bairros em que os habitantes tem rendimento nominal mensal médio acima da média de Curitiba: Centro, São Francisco e Centro Cívico. Os primeiros situados na faixa de 01 desvio padrão acima da média e o último com 02 desvios padrão acima da média do rendimento em Curitiba.

Um outlier figura entre os bairros de menor rendimento nominal mensal médio: Prado Velho, com desvio padrão abaixo da média de Curitiba. 
Outros 15 bairros tem as mais elevadas taxas de ocorrências de uso de drogas ${ }^{38}$. Destes, 08 integram o conjunto de bairros de rendimento nominal mensal médio acima da média ${ }^{39}$ e 07 integram o conjunto de bairros de rendimento nominal mensal médio abaixo da média de Curitiba. ${ }^{40}$

Figura 3 - BOXPLOT E BOXMAP REFERENTES À VARIÁVEL TAXA MÉDIA DE TRÁFICO DE DROGAS (2008-2017).
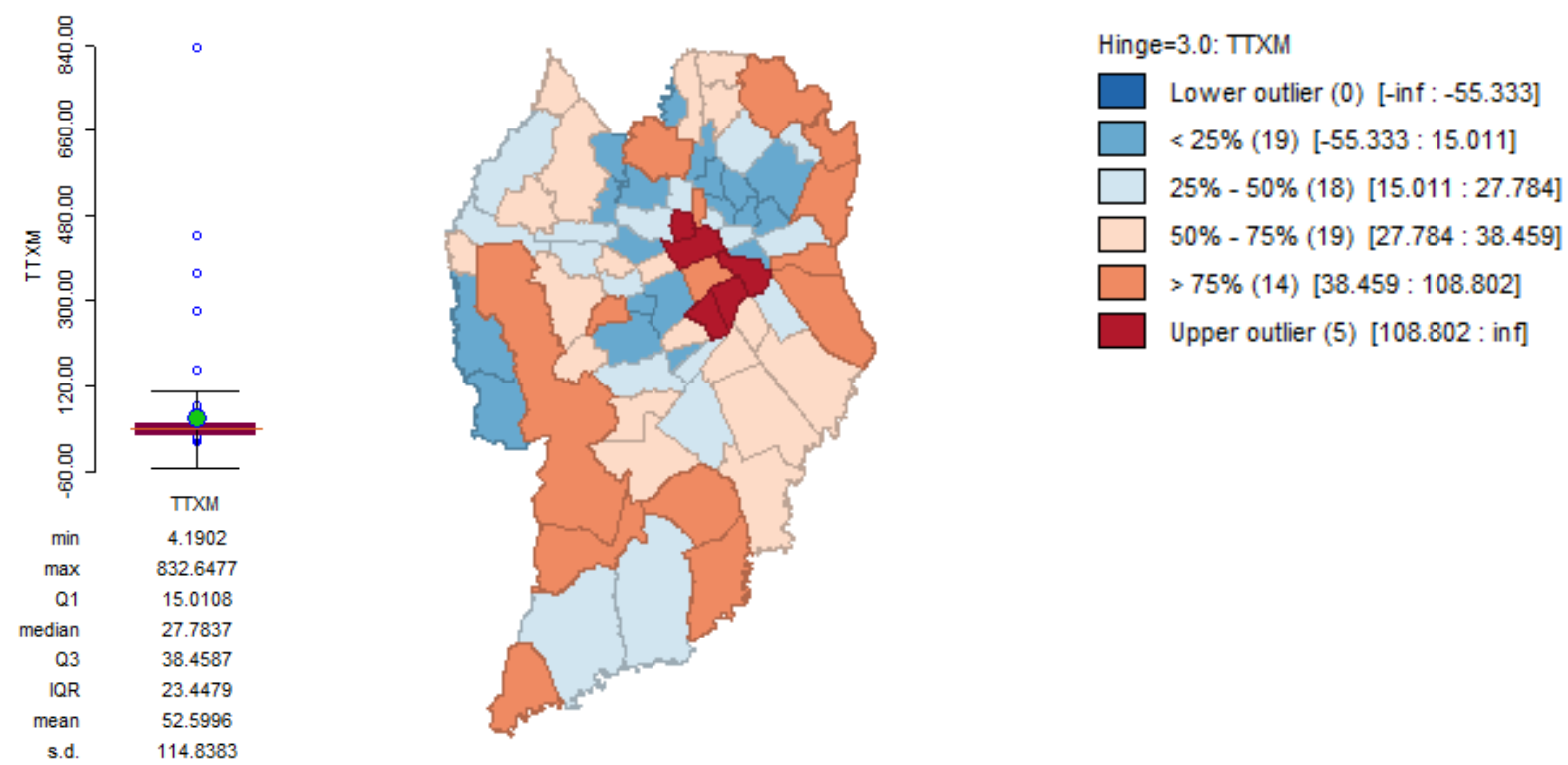

Fonte: o autor com dados da SESP/PR e uso do software Geoda.

A análise dos dados indica que a taxa média de ocorrências de tráfico de drogas para o período de 2008 a 2017 varia entre 4,12 e 832,64 casos por cem mil habitantes. A média é de 52,59 ocorrências por cem mil habitantes. O gráfico mostra cinco outliers: Centro, Jardim Botânico, São Francisco, Parolin e Prado Velho.

\footnotetext{
${ }^{38}$ Alto da Glória, Batel, Butiatuvinha, Cascatinha, Guabirotuba, Jardim Botânico, Santa Felicidade, Santo Inácio, São Braz, São João, Sítio Cercado, Santa Quitéria, Parolin, Orleans e Rebouças.

${ }^{39}$ Alto da Glória, Batel, Cascatinha, Guabirotuba, Jardim Botânico, Santo Inácio, São João e Rebouças.

${ }^{40}$ Butiatuvinha, Santa Felicidade, São Braz, Sítio Cercado, Santa Quitéria, Parolin e Orleans.
} 
Dentre os outliers encontrados, três figuram entre os bairros em que os habitantes tem rendimento nominal mensal médio acima da média de Curitiba: Centro, São Francisco e Jardim Botânico. Todos estão situados na faixa de 01 desvio padrão acima da média.

Outros dois outliers, Parolin e Prado Velho, estão entre os bairros em que os habitantes tem menor rendimento nominal mensal médio, na faixa de 01 e 02 desvios padrão abaixo da média de Curitiba, respectivamente.

Outros 14 bairros têm as mais altas taxas médias de ocorrências de tráfico de drogas ${ }^{41}$. Destes, 02 integram o conjunto de bairros de rendimento nominal mensal médio acima da média 42 e 12 integram o conjunto de bairros de rendimento nominal mensal médio abaixo da média de Curitiba. ${ }^{43}$

\section{CONCLUSÃO}

Curitiba é uma das cidades mais desenvolvidas do País. Contudo, isso não impede que a distribuição da riqueza pelo espaço urbano seja heterogênea. A região central concentra os bairros mais ricos. Os bairros mais pobres são relegados à periferia. As ocorrências policiais relacionadas a drogas também se distribuem de forma desigual. Os bairros de menor rendimento concentram a maior parte delas.

Os outliers em relação ao uso de drogas que figuram entre os bairros que tem renda acima da média são: Centro, São Francisco e Centro Cívico. O Centro, com uma população de 37.283 pessoas, figura entre os bairros de maior renda e responde, sozinho, por $22,56 \%$ das ocorrências de uso e 22,69\% das ocorrências de tráfico de toda Curitiba. Todavia, a intensa atividade econômica acarreta um trânsito intenso de pessoas que ali não residem, o que poderíamos chamar de população flutuante. É razoável admitir que ocorrências policiais, em

\footnotetext{
41 Atuba, Bairro Alto, Capão da Imbuia, Caximba, Cajuru, Centro Cívico, Cidade Industrial, Ganchinho, Pilarzinho, Rebouças, Santa Quitéria, Santa Cândida, Sítio Cercado e Tatuquara.

${ }^{42}$ Centro Cívico e Rebouças.

43 Atuba, Bairro Alto, Capão da Imbuia, Caximba, Cajuru, Cidade Industrial, Ganchinho, Pilarzinho, Santa Quitéria, Santa Cândida, Sítio Cercado e Tatuquara.
} 
alguma medida, vão incidir sobre essa população, gerando um incremento aos números, com reflexos nas taxas por cem mil habitantes. São Francisco e Centro Cívico são vizinhos ao Centro e guardam as mesmas características. Outro outlier em relação a uso de drogas é o Prado Velho. Localizado na região central da cidade, tem renda de $\mathrm{R}$ \$ 691,79 (70 ${ }^{\mathrm{a}}$ posição) e taxa média de ocorrências de uso de drogas de 862,27 por cem mil habitantes, segunda maior taxa dentre todos os bairros. Neste bairro encontra-se um ponto de extrema pobreza e violência: a "Vila Torres".

Em relação às ocorrências de tráfico de drogas, Centro, São Francisco e Jardim Botânico figuram entre os bairros que tem rendimento acima da média de Curitiba. O Centro, em particular, tem a maior quantidade de ocorrências de uso e tráfico em números absolutos, muito embora ocupe somente a décima quarta posição em termos populacionais. O demasiado número de ocorrências pode ser explicado pela alta demanda e consequente oferta de drogas, somandose ao grande fluxo diário de pessoas e ao policiamento intensificado pela elevada circulação de pessoas e grande concentração de bens e serviços. São Francisco, vizinho ao Centro, segue a mesma tendência. O Jardim Botânico, muito embora esteja entre os bairros de renda acima da média, é vizinho ao Prado Velho, outlier também em relação a ocorrências de tráfico de drogas. O bairro Parolin fecha a lista dos bairros que se destacam. Prado Velho e Parolin estão entre os bairros em que os habitantes tem menor rendimento nominal mensal médio. No Parolin fica localizado outro ponto de pobreza e violência: a "Favela do Parolin".

Desconsiderando os outliers, diferentemente do que acontece em relação às ocorrências de uso de drogas, em que há uma certa divisão entre ricos e pobres ( 08 bairros ricos e 07 pobres), o tráfico impera nas regiões que têm rendimentos abaixo da média ( 02 bairros ricos e 12 pobres).

Intui-se, a partir das considerações acima, que, de fato, pode haver uma seletividade das agências estatais na repressão ao tráfico de drogas. A análise de regressão buscou aclarar um pouco mais a questão. O resultado de que $35 \%$ da variação da taxa de ocorrências policiais relacionadas a tráfico de drogas pode ser explicada pela variação do número de domicílios permanentes em casa de cômodos, cortiço ou cabeça de porco e taxa de pretos e pardos, variáveis estas relacionadas aos aspectos de seletividade citados pela doutrina (visibilidade da infração, adequação do autor ao estereótipo do criminoso, incapacidade do agente em beneficiar-se da corrupção ou prevaricação e vulnerabilidade à violência) confere plausibilidade à hipótese de seletividade na repressão estatal ao tráfico de drogas. 


\section{REFERÊNCIAS BIBLIOGRÁFICAS}

ALMEIDA, Eduardo. Econometria Espacial Aplicada. Campinas: Alinea, 2012.

BRASIL. Lei $\mathbf{n}^{\mathbf{0}}$ 11.343, de 23 de agosto de 2006. Institui o Sistema Nacional de Políticas Públicas sobre Drogas - Sisnad; prescreve medidas para prevenção do uso indevido, atenção e reinserção social de usuários e dependentes de drogas; estabelece normas para repressão à produção não autorizada e ao tráfico ilícito de drogas; define crimes e dá outras providências.

CURITIBA. Lei $\mathbf{n}^{\mathbf{0}}$ 12.667/08, de 4 de abril de 2008. Cria a Secretaria Antidrogas Municipal - SAM, altera dispositivos da Lei $\mathrm{N}^{\circ}$ 7.671, de 10 de junho De 1991, e suas alterações, e da Lei $\mathrm{N}^{\circ} 11.100$, de 21 de junho de 2004, que autoriza o executivo municipal a criar o Conselho Municipal de Políticas Sobre Drogas de Curitiba e dá outras providências.

D’ELIA FILHO, Orlando Zaccone. Acionistas do Nada. Rio de Janeiro: Revan, 2007.

DRUCK, Suzana; CARVALHO, Marília Sá; CÂMARA, Gilberto. Análise Espacial de Dados Geográficos. Brasília: EMBRAPA, 2004.

FURTADO, Bernardo. Mercado imobiliário e a importância das características ocais: uma análise quantílico-espacial de preços ledônicos em Belo Horizonte. Análise Econômica. Porto Alegre, n. 47, set. 2007.

Geoda. Versão 1.12.1.161. [S.1.]: The R Foundation for Statistical Computing, 2018.

GIL, Antônio Carlos. Métodos e Técnicas de Pesquisa Social. 6. ed. São Paulo: Atlas, 2008.

GLOBAL FINANCIAL INTEGRITY (GFI) Transnational Crime and the Developing World. Washington, DC. 2017.

GRILLO, Carolina Christoph; POLICARPO, Frederico; VERÍSSIMO, Marcos. A "dura" e o "desenrolo": efeitos práticos da nova lei de drogas no Rio de Janeiro. Revista de Sociologia e Política. Curitiba, v. 19, n. 40, p. 135-148, out. 2011. Disponível em: http://www.scielo.br/scielo.php?pid=S0104-

44782011000300010\&script=sci_abstract\&tlng=pt

HARSTELN, Rodrigo Ebert; AMARAL FILHO, Juarez Ramos do; WERNER, Liane. Análise de capacidade de dados não normais de um sistema de tratamento de efluente industrial. INGEPRO - Inovação, Gestão e Produção, v. 02, n. 11, p. 13-25, 2010. Disponível em: http://www.ingepro.com.br/Publ_2010/Nov/309-916-1-PB.pdf

KARAM, Maria Lucia. "Guerra às Drogas" e criminalização da pobreza. In: Estudos críticos sobre o sistema penal: homenagem ao Professor Doutor Juarez Cirino dos Santos por seu $\mathbf{7 0}^{\circ}$ aniversário. Curitiba: LedZe, 2012. 
LECHENAKOSKI, Bryan Breno. A Subjetividade na Diferenciação entre o Usuário e o Traficante - Critérios Perniciosos para o Acusado. Revista Núcleo Jurídico. Florianópolis. v. 1. p. 9-31. 2017.

MARQUES, Ana Paula da Silva; HOLZSCHUH, Marcelo Leandro; TACHIBANA, Vilma Mayumi; IMAI, Nilton Nobuhiro. Análise Exploratória de Dados de Área para Índices de Furto na Mesorregião de Presidente Prudente-SP. III Simpósio Brasileiro de Ciências Geodésicas e Tecnologias da Geoinformação. Recife - PE, 27-30 jul. 2010.

MARTINS, Gilberto de Andrade; DOMINGUES, Osmar. Estatística geral e aplicada. 6. ed. São Paulo: Atlas, 2019.

Microsoft Excel 2013. Versão 15.0.5075.1001. [S.1.]: Microsoft Corporation, 2013.

NAGAKI, Marcos Antônio Feijó. Aglomerações Produtivas nos Setores de Atividade Econômica do Ceará: Análise Temporal e Espacial. Dissertação (Mestrado Profissional em Economia do Setor Público Economia). Universidade Federal do Ceará. Fortaleza, 2017.

NAKABASHI, Luciano; FELIPE, Evânio. Capital Humano nos Municípios Paranaenses. Análise Econômica, Porto Alegre, n. 47, 2000. Disponível em: https://seer.ufrgs.br/AnaliseEconomica/article/view/10877

PINO, Francisco Alberto. A Questão da Não Normalidade: uma revisão. Rev. de Economia Agrícola, v. 61, n. 2, p. 17-33, 2014. Disponível em: http://www.iea.sp.gov.br/ftpiea/publicar/rea2014-2/rea2-22014.pdf

PRADO, Fernanda de Almeida; BERVEGLIERI, Adilson; TACHIBANA, Vilma Mayumi; IMAI, Nilton Nobuhiro. Aplicação e Análise de Modelos de Regressão Clássica e Espacial para os Distritos da Cidade de São Paulo. III Simpósio Brasileiro de Ciências Geodésicas e Tecnologias da Geoinformação. Recife - PE, 27-30 jul. 2010.

SILVA, Adriano Cândido; RODRIGUES, Ricardo SAAR. Indicadores de Tempo de Passagem entre Apresentação na Sede e Início da Jornada em Trem da Tripulação dos Trens da Malha Sudeste na Região do Rio de Janeiro. Monografia (Especialização em Métodos Estatísticos Computacionais). Instituto de Ciências Exatas da Universidade Federal de Juiz de Fora, 2013.

SILVA Leilianne Francielle. O princípio da intervenção mínima como problemática social: a dimensão constitucional, penal e moral. Revista Juris Poiesis ano 19, n 21, set.-dez.. 2016. Disponível em: http://revistaadmmade.estacio.br/index.php/jurispoiesis/article/viewFile/2977/1349

VIRGILLITO, Salvatore Benito. Estatística aplicada. 1. ed. São Paulo: Saraiva, 2017.

Data de Submissão: 27/11/2020

Data de Aceite: 23/03/2021 